\title{
Letter to Editor: Social Resilience as a Protection Against COVID-19 Outbreak
}

\author{
Alireza Atarodi ${ }^{1}$ (D), Ahmadreza Atarodi ${ }^{*}$ (D) \\ 1. Department of Knowledge and Information Science, Paramedical College and Social Development \& Health Promotion Research Center, Gonabad \\ University of Medical Sciences, Gonabad, Iran. \\ 2. School of Medicine, Student Research Committee, Gonabad University of Medical Sciences, Gonabad, Iran.
}

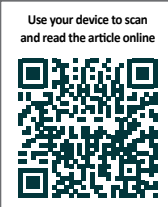

Citation Atarodi A, Atarodi A. Social Resilience as a Protection Against COVID-19 Outbreak. Journal of Research \& Health. 2020; 10(5):275-276. http://dx.doi.org/10.32598/JRH.10.5.773.12

doi: : http://dx.doi.org/10.32598/JRH.10.5.773.12

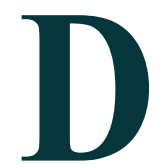

isasters whether natural or man-made occur from time to time and are accompanied by financial and human casualties. Their harmful effects are sometimes immense mostly on the poor, the illiterate, and marginalized people. This condition may be worsened when the governments have no financial support for the poor to save their lives. Even some groups are neglected by the country's ruling system since they seem to be useless and have even incurred costs for the country. Then, what can be done to find a way out of the said problems? As some research results show, social resiliency can be beneficial to cope with this neglect, at least an emotional relief, when there is no other way. Social resilience is defined as the ability of a human community to cope with and adapt to stresses such as social, political, environmental, or economic changes.

Sam Aram and his colleagues (2017) defined social resilience as people's capacity and systems that facilitate organizational performance to maintain functional relationships despite the turmoil. Social resilience can drive a crisis-stricken society from a socially unbalanced state to a socially balanced one and restores the functions of the society. A resilient system or community has recovery capacity and the ability to return to balance after an incident or challenge [1].
Natural hazards and climate change affect people, economies, and societies. Not only are they a consequence of the exposure to a physical hazard, but also they are shaped by social, political, and economic factors that cause vulnerability [2]

There can be different causes for risk factors based on different areas, people, beliefs, supports, families, feelings, sex, living situations, and so on. For example, the results of some studies have found that happier people have a strong purpose in life, experience higher levels of self-efficacy, and believe in their control over their situations, and take a smoother path recovering after a disaster. Some of these personality factors are protective, even in economic hardship, and can lead to better health outcomes and recovery after any challenges and disasters [3].

It seems that the research results on resiliency are different and varied since certain protective behaviors that may help one group in one society do not necessarily help another group in the same society and or in a different society. Then, resiliency is not a stable trait and behavior but fluctuates from time to time or from a situation to another based on the environmental changes [4].

Now, what and how social resiliency can be built and achieved? At first, families should train children

\footnotetext{
* Corresponding Author:

Ahmadreza Atarodi

Address: School of Medicine, Student Research Committee, Gonabad University of Medical Sciences, Gonabad, Iran

Phone: +98 (915) 5331034

E-mail: aratarodi1387@yahoo.com
} 
at home. Then schools, universities, and every educational and training center can be involved in building social resiliency. The society, ruling system, religion, and most institutions in the communities are in part responsible to improve and empower individuals in their society to build resiliency. This power and feature are necessary to save and control them in situations such as we are confronted with it today, like the COVID-19 outbreak or the like. A case in point was Taiwan who built community disaster resilience to cope with the confronted challenges in the country [5].

Thus, social resilience is the psychological strength and power in society to help the people at risk to be empowered enough to cope with the challenges, disasters, disease outbreak, stress, and most of the outcomes resulted from a different and unusual crisis in a community. The characteristics an individual should have to build social resiliency include psychological power to cope with stress, tension, and hardship in crisis; a belief that a challenge is an opportunity, not a threat; knowing the ways to prevent, control, and stop it; being kind and love the people and try to solve their problems; committing to saving lives regardless of race, gender, and class; having self-efficacy in stress and chaotic situations [5]; resisting on hardship; being realistic and acting as a joker and giving positive energy to the surrounding environment; using an action-oriented approach, being patient, tolerant, optimistic with good faith and beliefs.

A resilient person acts based on knowledge and science, knows and accepts the facts and realities, not rumors and gossips, is flexible and willing to overcome obstacles, has the emotional strength to control his or her feelings. A resilient one has a road map and promotes an inclusive culture and she or he is a full lover. Now, the key principle for policymakers and social practitioners is to interpret the resilience and how it can be grasped and know that how to bring disparate groups people, institutions, disciplines, and scales together, and how to deeply inject values and navigate tradeoffs in resilience between groups. Policymakers and authorities should make the best of mass and social media by reframing issues to help people, affected by stresses and at present, the COVID-19 pandemic that has affected all aspects of human life, including public health and we do not know when it will end [6].

Authorities should be responsible for securing people with the least cost. Policymakers, the ruling system, and scholars should know themselves responsible to empower individuals and societies enough to cope with the sudden impact of outbreaks, crises, or disasters, and to restore as quickly as possible their ability to function well. At last but not the least, the families should train children for social resiliency from childhood and let them experience life and inject resiliency to them and children should learn to be patient, as well.

\section{Ethical Considerations}

\section{Compliance with ethical guidelines}

All ethical principles are considered in this article.

\section{Authors' contributions}

All authors contributed in preparing this article.

\section{Conflict of interest}

The authors declared no conflict of interest.

\section{References}

[1] Sam Aram E, Mansouri S. [Explaining the concept of social resilience and analyzing its measurement indicators (Persian)]. Soc Dev Welfare Plan. 2018; 8(32):1-31. [DOI:10.22054/ QJSD.2017.8424]

[2] Arnold M, de Cosmo S. Building social resilience protecting and empowering those most at risk. [Internet]. 2015 [Updated 2015]. Available from: https://www.gfdrr.org/sites/default/files/publication/Building-Social-Resilience-Protecting-and-Empowering-Those-Most-at-Risk.pdf

[3] Schaefer SM, Boylan JM, van Reekum CM, Lapate RC, Norris CJ, Ryff CD, et al. Purpose in life predicts better emotional recovery from negative stimuli. PLoS One. 2013; 8(11):e80329. [DOI:10.1371/journal.pone.0080329] [PMID] [PMCID]

[4] Klika JB, Herrenkohl TI. A review of developmental research on resilience in maltreated children. Trauma Violence Abuse. 2013; 14(3):222-34. [DOI:10.1177/1524838013487808] [PMID] [PMCID]

[5] Chen LC, Wang YW. Building community capacity for disaster resilience in Taiwan. J Disaster Res. 2010; 5(2):138-46. [DOI:10.20965/jdr.2010.p0138]

[6] Alami A. Editorial: COVID-19: Emergence, spread, and implication for public health. J Res Health. 2020; 10(3):131-4. [DOI:10.32598/JRH.10.3.303.4] 